\title{
ORIGINAL
}

\section{Association of myeloperoxidase G-463A gene polymorphism with diabetic nephropathy in Japanese type 2 diabetic subjects}

\author{
Naoto Katakami ${ }^{1,2)}$, Shinji Kume ${ }^{3)}$, Hideaki Kaneto ${ }^{1)}$, Takashi Uzu ${ }^{3)}$, Atsunori Kashiwagi ${ }^{3)}$, \\ Yoshimitsu Yamasaki ${ }^{1)}$, Hiroshi Maegawa ${ }^{3)}$ and Iichiro Shimomura' ${ }^{1)}$ \\ 1) Department of Metabolic Medicine, Osaka University Graduate School of Medicine, Suita 565-0871, Japan \\ 2) Department of Metabolism and Atherosclerosis, Osaka University Graduate School of Medicine, Suita 565-0871, Japan \\ 3) Department of Medicine, Shiga University of Medical Science, Otsu 520-2192, Japan
}

\begin{abstract}
It is possible that myeloperoxidase (MPO) contributes to the pathogenesis of diabetic nephropathy through the production of reactive oxygen species and $\mathrm{HOCl} / \mathrm{OCl}^{-}$. In this study, we examined the relationship between renal damage and $M P O$ G-463A gene polymorphism that is associated with its transcription activity in diabetic patients. We evaluated the association between $M P O$ G-463A polymorphism and the prevalence of proteinuria and estimated GFR (eGFR) in 1448 Japanese type 2 diabetic subjects. The prevalence of macroalbuminuria was higher as the number of $\mathrm{G}$ alleles increased (GG $(7.6 \%)$, GA $(3.8 \%)$, AA $(0.0 \%), p$ for trend=0.0269). The number of $\mathrm{G}$ alleles was significantly associated with macroalbuminuria (odds ratio 2.12, 95\% CI 1.06-4.24, $p=0.0344$ ) even after adjustment for conventional risk factors. Inversely, eGFR was lower as the number of G alleles increased (GG $\left(76.7 \pm 20.7 \mathrm{~mL} / \mathrm{min} / 1.73 \mathrm{~m}^{2}\right), \mathrm{GA}(81.0 \pm 22.8 \mathrm{~mL} /$ $\left.\mathrm{min} / 1.73 \mathrm{~m}^{2}\right)$, AA $\left(92.0 \pm 23.1 \mathrm{~mL} / \mathrm{min} / 1.73 \mathrm{~m}^{2}\right), p$ for trend=0.0025) and the number of G allele was an independent risk factor for a low eGFR $(\beta=-0.072, p=0.003)$. We also examined the association between MPO expression and several stages of renal damage in a high-fat diet-induced diabetic mouse model. The proteinuria-induced increase in MPO expression was markedly enhanced in diabetic mice, and MPO expression was significantly correlated with the severity of kidney damage. In conclusion, it is likely that the $\mathrm{G}$ allele of the $M P O \mathrm{G}-476 \mathrm{~T}$ polymorphism is a susceptibility allele for renal injury in type 2 diabetic patients.
\end{abstract}

Keywords: Diabetes, Myeloperoxidase, Polymorphism, Single nucleotide polymorphisms (SNP), Nephropathy

MYELOPEROXIDASE (MPO), a member of the mammalian heme peroxidase superfamily, is stored within the azurophilic granules of circulating neutrophils, monocytes, and some tissue macrophage populations $[1,2]$. The catalytic activity of MPO results in the generation of various reactive oxidants and diffusible radical species [1]. Although MPO-derived reactive oxygen species (ROS) play an important role in killing

Submitted Sep. 11, 2012; Accepted Nov. 21, 2012 as EJ12-0345

Released online in J-STAGE as advance publication Dec. 24, 2012

Correspondence to: Naoto Katakami, M.D., Ph.D., Department of Metabolic Medicine, Osaka University Graduate School of Medicine, 2-2 Yamadaoka, Suita, Osaka 565-0871, Japan.

E-mail:katakami@endmet.med.osaka-u.ac.jp

* Naoto Katakami and Shinji Kume contribute equally to this work and are co-first authors.

Abbreviations: $\mathrm{Cr}$, creatinine; FFA, free fatty acid; HFD, highfat diet; MPO, Myeloperoxidase; ND, normal diet; ROS, reactive oxygen species invading parasites and pathogens, they could also promote host tissue injury through oxidative modification of proteins, lipids, and nucleic acids [3-6], leading to a wide range of chronic inflammatory diseases including kidney disease. In addition, MPO generates hypochlorous acid/hypochlorite $\left(\mathrm{HOCl} / \mathrm{OCl}^{-}\right)$from hydrogen peroxide in the presence of chloride ions, which may cause dysfunction of cells in different compartments of the kidney through the generation of a variety of chlorinated protein and lipid adducts.

Indeed, previous studies implied that MPO plays roles in the pathogenesis of several renal diseases such as acute immune complex crescentic glomerulonephritis [7], membranous glomerulonephritis [8], and ischemia/reperfusion injury [9]. It is possible that MPO also contributes to the pathogenesis of diabetic nephropathy through the production of ROS and $\mathrm{HOCl} / \mathrm{OCl}^{-}$, since increased production of ROS plays an important role 
in the pathogenesis of renal injury in diabetes mellitus [10-13]. However, so far, very little information has been obtained about the association between MPO and renal dysfunction in diabetic patients.

The G-463A gene polymorphism (rs2333227), a G/A substitution at SP1 transcription factor binding site in $M P O$ gene, is associated with its transcription activity and the G allele and GG genotype have been reported to be associated with increased MPO expression $[14,15]$. However, there have been very few studies on the association of this polymorphism and the risk of diabetic nephropathy.

In this study, we examined the relationship between this polymorphism and kidney damage in a cohort of Japanese type 2 diabetic patients. In addition, we investigated whether MPO expression might be related to kidney damage in type 2 diabetes, using a high-fat diet (HFD)-induced diabetic mouse model.

\section{Materials and Methods}

\section{Subjects}

All the Japanese type 2 diabetic subjects who periodically attended the outpatient clinics of diabetes in 7 participating hospitals (Osaka University Medical Hospital, Ehime Prefectural Central Hospital, Ehime Prefectural Imabari Hospital, Imamura Clinic, Ishibashi Clinic, Naka Memorial Clinic, Kawai Clinic) during 1 year (January-December period in 2005) in Japan were asked to participate in this study. We considered subjects eligible when they had type 2 diabetes diagnosed by diabetologists based on Japan Diabetes Society's criteria. After all, a total of 1448 subjects (males, $61.7 \%$; age, $60.6 \pm 9.7$ years $($ mean $\pm \mathrm{SD}) ; \mathrm{HbA} 1 \mathrm{c} 7.3 \pm 1.3 \%$ ) were enrolled in the present study. The patients' characteristics and their medication are listed in Table 1. The study protocol was approved by the committees on the ethics of human research of Osaka University Graduate School of Medicine. A written informed consent was obtained from all the participants after a full explanation of the study.

\section{Clinical and biochemical analysis}

Fasting blood samples were collected and $\mathrm{HbA1c}$, serum total and HDL cholesterol, and serum triglyceride levels were measured using standard laboratory protocols. HbA1c was measured by high-performance liquid chromatography using a set of calibrators assigned by the Japan Diabetes Society (normal range
4.3-5.8\%). According to correlation analysis, $\mathrm{HbA1c}$ values in Japan were estimated to be $0.4 \%$ lower than those measured by the National Glycohemoglobin Standardization Program (NGSP) [16]. To standardize $\mathrm{HbA} 1 \mathrm{c}$ values to NGSP units, $0.4 \%$ was added to the measured values and expressed as $\mathrm{HbA} 1 \mathrm{c}$-equivalent NGSP units in the current study. Serum MPO levels were measured in randomly selected 174 subjects using enzyme-linked immunosorbent assay kits (R\&D Systems, Inc, Minneapolis, USA). The inter-assay and intra-assay variability of the MPO test was $8.3 \%$ and $7.7 \%$, respectively. The determination of hypertension (defined as systolic blood pressure $\geq 130 \mathrm{mmHg}$ or diastolic blood pressure $\geq 80 \mathrm{mmHg}$ or having been treated for hypertension) and dyslipidemia (defined as serum LDL cholesterol $\geq 120 \mathrm{mg} / \mathrm{dL}$ or serum triglyceride (TG) $\geq 150 \mathrm{mg} / \mathrm{dL}$ or HDL-cholesterol $<40 \mathrm{mg} / \mathrm{dL}$ or having been treated for dyslipidemia) was based on the Japan Diabetes Society's criteria. Smoking status was evaluated as follows; a value of 0 and 1 were assigned to subjects when Brinkman's Index (the number of cigarettes per day x smoking years) was less than 200 and greater than 200, respectively. Urinary albumin and creatinine $(\mathrm{Cr})$ concentrations were determined using early morning spot urine. Nephropathy was graded as follows: normoalbuminuria, urinary albumin excretion less than $30 \mathrm{mg} / \mathrm{g} \mathrm{Cr}$; microalbuminuria, 30 to $300 \mathrm{mg} / \mathrm{g}$ $\mathrm{Cr}$; or macroalbuminuria, more than $300 \mathrm{mg} / \mathrm{g}$ Cr. GFR was estimated using the new equation proposed by the Japanese Society of Nephrology as follows: eGFR $\left(\mathrm{mL} / \mathrm{min} / 1.73 \mathrm{~m}^{2}\right)=194 \times \mathrm{Cr}^{-1.094} \times \mathrm{Age}^{-0.287} \times 0.739$ (if female) [17].

\section{Genetic analysis}

Venous blood was collected from each subject and genomic DNA was isolated with a DNA isolation kit (Qiagen). The genotypes of the MPO gene G-463A polymorphism were determined with a fluorescenceor colorimetry-based allele-specific DNA-primer probe assay system as previously described [18]. The average genotyping success rate was $99.7 \%$ and the genotyping accuracy was $100 \%$, which was determined from the genotype concordance between 500 duplicate samples.

\section{Animal protocol}

All procedures were performed in accordance with the guidelines of the Research Center for Animal Life Science of Shiga University of Medical Science. Sixweek-old male C57BL/6 mice were purchased from 
Table 1 Clinical characteristics of the subjects in two genotype groups

\begin{tabular}{|c|c|c|c|c|}
\hline $\begin{array}{l}G-463 \mathrm{~A} \text { polymorphism of the } \\
\text { myeloperoxidase }(M P O) \text { gene }\end{array}$ & $\begin{array}{c}\text { Total } \\
(\mathrm{n}=1448)\end{array}$ & $\begin{array}{c}\mathrm{G} / \mathrm{G} \\
(\mathrm{n}=1204)\end{array}$ & $\begin{array}{l}\mathrm{G} / \mathrm{A} \text { or } \mathrm{A} / \mathrm{A} \\
(\mathrm{n}=244)\end{array}$ & $p$ value \\
\hline Gender (male / female) & $892 / 556$ & $755 / 449$ & $137 / 107$ & NS \\
\hline Age (years) & $60.6 \pm 9.7$ & $60.8 \pm 9.6$ & $59.7 \pm 9.7$ & NS \\
\hline Smoking status $($ B.I. $<200 / \geq 200)$ & $746 / 702$ & $607 / 597$ & $139 / 105$ & NS \\
\hline Presence of obesity $(\%)$ & $562(38.8 \%)$ & $463(38.5 \%)$ & $99(40.6 \%)$ & NS \\
\hline Body mass index $\left(\mathrm{kg} / \mathrm{m}^{2}\right)$ & $24.4 \pm 3.7$ & $24.4 \pm 3.7$ & $24.5 \pm 3.5$ & NS \\
\hline $\mathrm{HbA}_{1 \mathrm{C}}(\%)$ & $7.7 \pm 1.3$ & $7.7 \pm 1.3$ & $7.7 \pm 1.3$ & NS \\
\hline Duration of diabetes (years) & $11.1 \pm 8.0$ & $11.2 \pm 8.0$ & $11.0 \pm 8.3$ & NS \\
\hline Presence of hypertension (\%) & $1053(72.7 \%)$ & $877(72.8 \%)$ & $176(72.1 \%)$ & NS \\
\hline Systolic blood pressure (mmHg) & $131 \pm 14$ & $131 \pm 14$ & $130 \pm 13$ & NS \\
\hline Diastolic blood pressure (mmHg) & $75 \pm 10$ & $74 \pm 9$ & $75 \pm 9$ & NS \\
\hline Presence of dyslipidemia (\%) & $1064(73.5 \%)$ & $883(73.3 \%)$ & $181(74.2 \%)$ & NS \\
\hline Total-cholesterol (mg/dL) & $201 \pm 35$ & $200 \pm 35$ & $207 \pm 38$ & 0.004 \\
\hline HDL-cholesterol (mg/dL) & $56 \pm 17$ & $56 \pm 17$ & $56 \pm 17$ & NS \\
\hline Triglyceride (mg/dL) & $107(26-2233)$ & $107(26-1662)$ & $105.5(29-2233)$ & NS \\
\hline Ln-triglyceride (mg/dL) & $4.71 \pm 0.58$ & $4.71 \pm 0.57$ & $4.72 \pm 0.63$ & NS \\
\hline $\mathrm{Cr}(\mathrm{mg} / \mathrm{dL})$ & $0.86 \pm 2.28$ & $0.89 \pm 2.49$ & $0.73 \pm 0.27$ & NS \\
\hline $\mathrm{eGFR}\left(\mathrm{mL} / \mathrm{min} / 1.73 \mathrm{~m}^{2}\right)$ & $77.5 \pm 21.1$ & $76.7 \pm 20.7$ & $81.4 \pm 22.9$ & 0.0016 \\
\hline $\mathrm{eGFR}<60 \mathrm{~mL} / \mathrm{min} / 1.73 \mathrm{~m}^{2}(\%)$ & $270(18.6 \%)$ & $236(19.6 \%)$ & $34(13.9 \%)$ & 0.038 \\
\hline Urinary albumin excretion index (mg/gCr) & $16.3(0-7605)$ & $16.1(0-7605)$ & $16.9(0.5-3573)$ & NS \\
\hline Ln-UAE (mg/gCr) & $3.10 \pm 1.46$ & $3.11 \pm 1.47$ & $3.04 \pm 1.38$ & NS \\
\hline Proteinuria (normo/micro/macro) & $951 / 397 / 100$ & $791 / 322$ / 91 & $160 / 75 / 9$ & - \\
\hline Albuminuria $>30 \mathrm{mg} / \mathrm{gCr}(\%)$ & $497(34.3 \%)$ & $413(34.3 \%)$ & $84(34.4 \%)$ & NS \\
\hline Albuminuria $>300 \mathrm{mg} / \mathrm{gCr}(\%)$ & $100(6.9 \%)$ & $91(7.6 \%)$ & $9(3.7 \%)$ & 0.030 \\
\hline Antidiabetic drugs (yes / no) & $1232(85.1 \%)$ & $1024(85.0 \%)$ & $208(85.2 \%)$ & NS \\
\hline Antihypertensive drugs (yes / no) & $558(38.5 \%)$ & $467(38.8 \%)$ & $91(37.3 \%)$ & NS \\
\hline Antihyperlipidemic drugs (yes / no) & $347(24.0 \%)$ & $296(24.6 \%)$ & $51(20.9 \%)$ & NS \\
\hline Serum MPO (ng/mL) & $\begin{array}{l}287(12-3371) \\
\quad(n=174)\end{array}$ & $\begin{array}{l}320(12-3371) \\
\quad(n=151)\end{array}$ & $\begin{array}{c}212(46-743) \\
\quad(n=23)\end{array}$ & 0.049 \\
\hline Ln-serum MPO (ng/mL) & $5.74 \pm 0.97$ & $5.79 \pm 0.99$ & $5.35 \pm 0.78$ & 0.039 \\
\hline
\end{tabular}

Data are shown as numbers, means $\pm \mathrm{SD}$, or median (range). All the subjects were divided into two groups based on the major allele's recessive genetic models ( $G G$ genotype $v s . G A+A A$ genotype) and the parameters were compared among the groups. Quantitative data between the groups were compared by the 2-tailed unpaired $t$ test or Mann-Whitney test, depending on the distribution pattern of the data. Categorical data were analyzed with the $\chi^{2}$ test or Fisher's exact test. Nephropathy was graded as follows: normoalbuminuria, urinary albumin excretion less than $30 \mathrm{mg} / \mathrm{g} \mathrm{Cr}$; microalbuminuria, 30 to $300 \mathrm{mg} / \mathrm{g} \mathrm{Cr}$; or macroalbuminuria, more than $300 \mathrm{mg} / \mathrm{g}$ Cr. $p$-values over 0.05 were displayed as NS (not significant).

B. I., Brinkman's Index; Ln-, log-transformed; UAE, Urinary albumin excretion index; MPO, myeloperoxidase

CLEA Japan (Tokyo, Japan) and housed in cages under a 12-h light/12-h dark cycle. The normal diet (ND; $10 \%$ of total calories from fat) and high-fat diet (HFD; $60 \%$ of total calories from fat) were purchased from Research Diets (New Brunswick, NJ). In order to establish a mouse model of obese type 2 diabetes and microalbuminuria, we used the following protocol. After 2 weeks of acclimatization, the mice were fed with an ND or HFD for an additional 12 weeks, and then they were placed in metabolic balance cages to measure 24-h urinary albumin excretion [19]. At the 12 -week point, the mice were sacrificed and urinary albumin concentrations and serum cystatin C levels were measured with a commercially available ELISA kit Albuwell (Exocell, Philadelphia, PA) and Cystatin C (mouse) ELISA Kit (ALEXIS Biochemicals, CA). The urinary albumin was expressed as the total amount excreted during the 24-h urine collection [19].

To determine the effects of HFD-induced diabetes on proteinuria-induced renal injury, after 2 weeks of acclimatization, a second cohort of mice were maintained on an ND or HFD for 6 weeks, and then intraperitoneally injected with PBS (control) or free fatty acid (FFA)-non-depleted bovine serum albumin (protein- 
overload) for 11 days, as previously described [19]. For both of the animal experiments undertaken, each group contained eight mice. At the end of the experimental period, each of the animals' body weights, blood glucose and glycated hemoglobin levels were measured, as previously described [19]. Urinary protein concentrations were measured using the Bradford method. Kidney samples were also removed and collected as previously reported [19].

\section{$R N A$ extraction and quantitative real-time PCR}

Total RNA was isolated from the kidney of each group of mice to synthesize cDNA. The iQSYBR Green Supermix (Bio-Rad Laboratories, Hercules, CA) was used for real-time PCR (ABI Prism TM 7500 Sequence Detection System; Perkin-Elmer Applied Biosystems, Foster City, CA). The mRNA expression levels were quantified using the standard curve method and adjusted for the mRNA expression of $\beta$-actin as an internal control [19]. The following primer sequences were used (forward and reverse): $\beta$-actin, CGTGCGTGACATCAAAGAGAA and TGGATGC CACAGGATTCCAT; neutrophil gelatinase-associated lipocalin (Ngal), TACCCTGTATGGAAGAA CCAAGGA and CGGTGGGGACAGAGAAGATG; F4/80, CTTTGGCTATGGGCTTCCAGTC and GCA AGGAGGACAGAGTTTATCGTG; myeloperoxidase (MPO), GTGTCAAGTGGCTGTGCCTATC and AGT GGGGCTTCGTCTGTTGT.

\section{Cell culture study}

SV40-transformed murine mesangial, immortalized murine podocyte and murine proximal tubular cell lines were cultured as described previously [19]. After a 12-hour starvation period, cells were stimulated with FFA-non-depleted albumin $(30 \mathrm{mg} / \mathrm{mL})$ for 9 hours. Total RNA was isolated and cDNA was synthesized by reverse transcriptional PCR. cDNA was used for standard PCR to check the expression of MPO and $\beta$-actin.

\section{Statistical analysis}

All the subjects were divided into two groups based on the major allele's recessive genetic models ( $G G$ genotype $v s . G A+A A$ genotype) and the parameters were compared between the groups. Quantitative data between the groups were compared by the 2-tailed unpaired $t$ test or Mann-Whitney test, depending on the distribution pattern of the data. Categorical data were analyzed with the $\chi^{2}$ test or Fisher's exact test. In the major allele's additive genetic model ( $G G$ genotype $<G A$ genotype < $A A$ genotype or $G G$ genotype $>G A$ genotype $>A A$ genotype), the associations between the polymorphism and variables were evaluated with the Pearson's univariate test or the Cochran-Armitage test.

Multiple logistic regression analyses were performed to evaluate the relationship between the presence of macroalbuminuria and the number of $\mathrm{G}$ alleles or the GG genotype of $M P O \mathrm{G}-463 \mathrm{~A}$ polymorphism. Following variables were included in the model: gender, age, duration of diabetes, HbAlc, body mass index (BMI), presence of hypertension, and presence of dyslipidemia. Forward and backward stepwise multivariate regression analyses were also performed to evaluate the relationship between eGFR and the following variables: gender (female $=0$, male $=1$ ), age, smoking status, duration of diabetes, $\mathrm{HbAlc}, \mathrm{BMI}$, presence of hypertension, presence of dyslipidemia, and the number of $\mathrm{G}$ alleles of $M P O \mathrm{G}-463 \mathrm{~A}$ polymorphism.

\section{Results}

\section{Association of MPO G-463A polymorphism and mac- roalbuminuria in T2DM subjects}

The prevalence of the G-463A genotypes was as follows: GG, 83.1\%; GA, 16.3\%; AA, 0.6\%; and the genotype distribution was in Hardy-Weinberg equilibrium. Since the number of subjects with GA and AA genotypes was low, we combined the subjects with GA and AA genotypes, and performed a statistical analysis between two groups: the subjects with GG and those with GA or AA genotypes. There were no associations between this polymorphism and clinical characteristics including gender, age, smoking status, BMI, $\mathrm{HbA} 1 \mathrm{c}$, duration of diabetes, presence of hypertension, presence of dyslipidemia, and administration of drugs (Table 1). However, serum MPO levels were significantly higher in subjects with GG genotype $(n=151)$ as compared to those with GA or AA genotype $(n=23)$ (median (range) 320 (12-3371) and 212 (46-743) ng/ $\mathrm{mL}$, respectively, $p=0.049$ ).

Among a total of 1448 subjects, 397 subjects were defined as having microalbuminuria and 100 subjects were defined as having macroalbuminuria. There were no significant associations between this polymorphism and the prevalence of patients with albuminuria $>30 \mathrm{mg} / \mathrm{gCr}$. However, the prevalence of macroalbuminuria $(>300 \mathrm{mg} / \mathrm{gCr})$ was higher as the number of $\mathrm{G}$ alleles increased (GG (7.6\%), GA (3.8\%), AA (0.0\%), 
$p$ value for trend $=0.0269)$ and was significantly higher in the subjects with GG genotype as compared to those with GA or AA genotype ( $7.6 \% v s .3 .7 \%, p=0.0297)$ (Table 1).

When subjects were divided into the subjects with the macroalbuminuria $(+)$ group $(\mathrm{n}=100)$ and the macroalbuminuria (-) group $(\mathrm{n}=1348)$, the frequency of $\mathrm{G}$ allele $(95.5 \%$ vs. $91.0 \%, p=0.0289)$, BMI $(25.3 \pm 4.9$ vs. $\left.24.3 \pm 3.6 \mathrm{~kg} / \mathrm{m}^{2}, p=0.0134\right)$, duration of diabetes (13.4 $\pm 7.8 v s .11 .0 \pm 8.0$ years, $p=0.0036)$, and presence of hypertension $(86.0 \%$ vs. $71.7 \%, p=0.0020)$ were significantly higher in the former as compared to the latter (Table 2). Next, a multiple logistic regression analysis was performed to evaluate the relationship between the presence of macroalbuminuria and the following variables: the GG genotype of $M P O$ G-463A polymorphism, gender, age, duration of diabetes, $\mathrm{HbAlc}$, BMI, presence of hypertension, and presence of dyslipidemia. This analysis revealed that the subjects with GG genotype had a significantly higher risk of macroalbuminuria as compared to the subjects with AA or GA genotype (OR 2.11 with 95\% CI 1.04$4.29, p=0.038$ ) even after adjustment for conventional risk factors (Table 3). In addition, another multiple logistic regression model showed that the number of $\mathrm{G}$ alleles of $M P O$ G-463A polymorphism was significantly associated with macroalbuminuria even after adjustment for conventional risk factors (Odds ratio $(\mathrm{OR})$ for 1-point increase in the number $\mathrm{G}$ allele $=2.12$ with $95 \%$ CI 1.06-4.24, $p=0.034$ ) (data not shown).

Table 2 Clinical characteristics of the study subjects with and without proteinuria

\begin{tabular}{|c|c|c|c|}
\hline & $\begin{array}{c}\text { proteinuria }(-) \\
(\mathrm{n}=1348)\end{array}$ & $\begin{array}{l}\text { proteinuria }(+) \\
(\mathrm{n}=100)\end{array}$ & $p$ \\
\hline Gender (male / female) & $824 / 524$ & $68 / 32$ & $\mathrm{NS}^{\mathrm{a}}$ \\
\hline $\operatorname{Age}(\mathrm{yr})$ & $60.5 \pm 9.7$ & $62.2 \pm 9.4$ & NS \\
\hline Smoking (B.I. < $200 / \geq 200$ ) & $698 / 650$ & $48 / 52$ & $\mathrm{NS}^{\mathrm{a}}$ \\
\hline Body mass index $\left(\mathrm{kg} / \mathrm{m}^{2}\right)$ & $24.3 \pm 3.6$ & $25.3 \pm 4.9$ & 0.0134 \\
\hline $\mathrm{HbA}_{1 \mathrm{C}}(\%)$ & $7.7 \pm 1.3$ & $8.0 \pm 1.5$ & NS \\
\hline Duration of diabetes (yr) & $11.0 \pm 8.0$ & $13.4 \pm 7.8$ & 0.0036 \\
\hline Presence of hypertension (\%) & $967(71.7 \%)$ & $86(86.0 \%)$ & $0.0020^{\mathrm{a}}$ \\
\hline Systolic blood pressure (mmHg) & $130 \pm 14$ & $137 \pm 16$ & $<0.001$ \\
\hline Diastolic blood pressure $(\mathrm{mmHg})$ & $75 \pm 10$ & $77 \pm 11$ & NS \\
\hline Presence of dyslipidemia (\%) & $988(73.3 \%)$ & $76(76.0 \%)$ & NS \\
\hline Presence of obesity (\%) & $517(38.4 \%)$ & $45(45.0 \%)$ & NS \\
\hline Total-cholesterol (mg/dL) & $201 \pm 35$ & $206 \pm 39$ & NS \\
\hline HDL-cholesterol (mg/dL) & $56 \pm 17$ & $53 \pm 15$ & NS \\
\hline Triglyceride (mg/dL) & $106(26-2233)$ & $127.5(38-516)$ & NS \\
\hline Ln-triglyceride (mg/dL) & $4.70 \pm 0.58$ & $4.81 \pm 0.54$ & NS \\
\hline eGFR $\left(\mathrm{ml} / \mathrm{min} / 1.73 \mathrm{~m}^{2}\right)$ & $78.2 \pm 20.2$ & $68.7 \pm 30.0$ & $<0.001$ \\
\hline \multicolumn{4}{|l|}{ Administration of } \\
\hline Antidiabetic drugs (\%) & $976(72.4 \%)$ & $76(76.0 \%)$ & $\mathrm{NS}^{\mathrm{a}}$ \\
\hline Antihypertensive drugs (\%) & $493(36.4 \%)$ & $65(65.0 \%)$ & $<0.001^{\mathrm{a}}$ \\
\hline Anti-hyperlipidemic drugs (\%) & $319(23.7 \%)$ & $28(28.0 \%)$ & $\mathrm{NS}^{\mathrm{a}}$ \\
\hline \multicolumn{4}{|l|}{ Allele frequency $(\%)$} \\
\hline $\mathrm{G}$ & 91.0 & 95.5 & $0.029^{\mathrm{a}}$ \\
\hline A & 9.0 & 4.5 & $0.029^{\mathrm{a}}$ \\
\hline Genotype frequency (\%) & & & NS (MDM) \\
\hline \multirow[t]{2}{*}{$\mathrm{GG}, \mathrm{GA}, \mathrm{AA}$} & $82.6 / 16.8 / 0.6$ & $91.0 / 9.0 / 0.0$ & $0.030(\mathrm{MRM})$ \\
\hline & & & 0.027 (MAM) \\
\hline Serum MPO (ng/mL) & $\begin{array}{c}193(12-3371) \\
(\mathrm{n}=158)\end{array}$ & $\begin{array}{c}301(54-1991) \\
(\mathrm{n}=16)\end{array}$ & NS \\
\hline
\end{tabular}

Data are shown as numbers (\%) or means \pm SD. In the major allele's dominant and the recessive genetic models, the associations between the polymorphism and variables were evaluated with the $\chi^{2}$ test ${ }^{(a)}$. In the major allele's additive genetic model, the associations between the polymorphism and variables were evaluated with the Cochran-Armitage test. $p$ values over 0.05 were displayed as NS (not significant).

B. I., Brinkman's Index; MDM, major allele's dominant model; MRM, major allele's recessive model; MAM, major allele's additive model; Ln-, log-transformed; MPO, myeloperoxidase. 
Table 3 Multivariate logistic regression analysis to identify independent determinants for proteinuria

\begin{tabular}{lcccccc}
\hline \multirow{2}{*}{ Parameters } & \multicolumn{2}{c}{ Model 1} & & \multicolumn{2}{c}{ Model 2} \\
\cline { 2 - 3 } \cline { 5 - 6 } & Odds ratio (95\%CI) & $p$ value & & Odds ratio (95\%CI) & $p$ value \\
\hline Gender (male) & $1.36(0.87-2.13)$ & NS & & $1.36(0.87-2.13)$ & NS \\
Age (years) & $1.02(0.99-1.04)$ & NS & & $1.02(0.99-1.04)$ & NS \\
Duration of diabetes (years) & $1.03(1.00-1.06)$ & 0.024 & & $1.03(1.00-1.06)$ & 0.024 \\
HbA1c (\%) & $1.17(1.01-1.36)$ & 0.043 & & $1.17(1.01-1.36)$ & 0.043 \\
Body mass index $\left(\mathrm{kg} / \mathrm{m}^{2}\right)$ & $1.08(1.02-1.14)$ & 0.008 & & $1.08(1.02-1.14)$ & 0.007 \\
Presence of hypertension & $2.15(1.19-3.86)$ & & 0.011 & & $2.15(1.19-3.86)$ & 0.011 \\
Presence of dyslipidemia & $1.02(0.63-1.67)$ & NS & & $1.03(0.63-1.67)$ & NS \\
-463G allele & $2.12(1.06-4.24)$ & 0.034 & & - & - \\
-436GG genotype & - & - & & $2.11(1.04-4.29)$ & 0.038 \\
\hline
\end{tabular}

Multivariate logistic regression analysis was done for 1448 type 2 diabetic patients to select variables significantly associated with an increase in the risk of proteinuria. The threshold of statistical significance was defined as $p<0.05$. Model 1; gender, age, duration of diabetes, $\mathrm{HbAlc}$, body mass index, presence of hypertension, presence of dyslipidemia, and the number of $-436 \mathrm{G}$ allele were included as independent variables.

Model 2; gender, age, duration of diabetes, HbAlc, body mass index, presence of hypertension, presence of dyslipidemia, and the number of -436GG genotype were included as independent variables.

NS, not significant

Inversely, eGFR was lower as the number of $\mathrm{G}$ alleles increased $\left(\mathrm{GG}\left(76.7 \pm 20.7 \mathrm{~mL} / \mathrm{min} / 1.73 \mathrm{~m}^{2}\right)\right.$, GA $\left(81.0 \pm 22.8 \mathrm{~mL} / \mathrm{min} / 1.73 \mathrm{~m}^{2}\right), \mathrm{AA}(92.0 \pm 23.1$ $\left.\mathrm{mL} / \mathrm{min} / 1.73 \mathrm{~m}^{2}\right), p$ value for trend $\left.=0.0025\right)$ and was significantly lower in subjects with GG genotype compared to those with GA or AA genotype (76.7 $\pm 20.7 v s$. $81.4 \pm 22.9 \mathrm{~mL} / \mathrm{min} / 1.73 \mathrm{~m}^{2}, p=0.0016$ ) (Supplementary Table). In univariate correlation analysis, eGFR was significantly correlated with the number of $\mathrm{G}$ alleles $(\mathrm{r}=-0.088, p=0.0008)$, age $(\mathrm{r}=-0.364, p<0.0001)$, duration of diabetes $(\mathrm{r}=-0.197, p<0.0001), \mathrm{HbA1} \mathrm{c}(\mathrm{r}=0.174$, $p<0.0001)$, BMI $(\mathrm{r}=0.053, p=0.0441)$ and presence of hypertension $(\mathrm{r}=-0.145, p<0.0001)$ (Table 4$)$. To examine whether the number of $\mathrm{G}$ allele is a determinant of eGFR independent of conventional risk factors, we performed a stepwise multivariate regression analysis with gender, age, smoking status, duration of diabetes, HbAlc, BMI, presence of hypertension, presence of dyslipidemia, and the number of $G$ alleles of $M P O \mathrm{G}-463 \mathrm{~A}$ polymorphism as independent variables and eGFR as objective variables. This analysis showed that the number of $\mathrm{G}$ allele was an independent risk factor for a low eGFR $(\beta=-0.072, p=0.003)$ (Table 4). We also performed a dichotomous trait analysis for CKD stage 3 (eGFR $<60 \mathrm{~mL} / \mathrm{min} / 1.73 \mathrm{~m}^{2}$ vs. eGFR $\left.\geq 60 \mathrm{~mL} / \mathrm{min} / 1.73 \mathrm{~m}^{2}\right)$. This analysis revealed that the frequency of $\mathrm{G}$ allele $(93.7 \%$ vs. $90.7 \%, p=0.028)$ and GG genotype ( $87.4 \% v s .82 .2 \%, p=0.038)$ were significantly higher in the subjects with low eGFR $(<60)$ as compared to those with preserved eGFR $(\geq 60)$ (Table
5). However, a multiple logistic regression analyses showed that neither the number of $\mathrm{G}$ allele nor $\mathrm{GG}$ genotype was independently associated with low eGFR after adjustment for conventional risk factors (OR 1.45; $95 \%$ CI $0.98-2.15, p=0.062$ and OR 1.42 ; $95 \%$ CI 0.95 $2.12, p=0.090$, respectively) (Table 6).

Furthermore, we also performed a series of analyses in which the patients with shorter duration of diabetes (less than 10 years) were excluded, since the control (nephropathy free) groups must include patients who will develop overt nephropathy later on. The results of these analyses were similar to those of the original analyses. The prevalence of macroalbuminuria $(>300 \mathrm{mg} / \mathrm{gCr}$ ) was significantly higher in the subjects with GG genotype as compared to the subjects with GA or AA genotype $(10.4 \% v s .4 .3 \%, p=0.037)$ (Supplementary Table 1 and 2). In addition, multiple logistic regression analyses showed that the number of $\mathrm{G}$ allele (OR 2.63; 95\%CI 1.63-6.70, $p=0.043$ ) as well as GG genotype (OR 2.64; 95\%CI 1.03-6.76, $p=0.044$ ) were independently associated with macroalbuminuria even after adjustment for conventional risk factors (Supplementary Table 3). Inversely, eGFR was significantly lower in subjects with GG genotype compared to those with GA or AA genotype (72.3 $\pm 20.5 v s$. $80.2 \pm 25.1 \mathrm{~mL} / \mathrm{min} / 1.73 \mathrm{~m}^{2}, p<0.001$ ) (Supplementary Table 1). The frequency of $\mathrm{G}$ allele $(94.5 \%$ vs. $90.8 \%$, $p=0.029)$ and that of GG genotype (89.0\% vs. $81.9 \%$, $p=0.028$ ) were significantly higher in the subjects with low eGFR as compared to those with preserved eGFR 
Table 4 Correlations between eGFR and variables

\begin{tabular}{|c|c|c|c|c|}
\hline & \multicolumn{2}{|c|}{ Univariate* } & \multicolumn{2}{|c|}{ Multivariate } \\
\hline & $r$ & $p$ & $\beta$ & $p$ \\
\hline Gender (male / female) & -0.074 & 0.0046 & -0.079 & 0.001 \\
\hline Age (yrs) & -0.364 & $<0.001$ & -0.304 & $<0.001$ \\
\hline Smoking (yes / no) & -0.025 & NS & NI & - \\
\hline Duration of DM (yrs) & -0.197 & $<0.001$ & -0.088 & 0.001 \\
\hline HbA1c (\%) & 0.174 & $<0.001$ & 0.122 & $<0.001$ \\
\hline BMI $\left(\mathrm{kg} / \mathrm{m}^{2}\right)$ & 0.053 & 0.0441 & NI & - \\
\hline Presence of hypertension & -0.145 & $<0.001$ & -0.101 & $<0.001$ \\
\hline Presence of dyslipidemia & -0.028 & NS & NI & - \\
\hline MPO -463G & -0.088 & 0.0008 & -0.072 & 0.003 \\
\hline$R^{2}$ & - & - & 0.176 & - \\
\hline
\end{tabular}

*Pearson's univariate correlation coefficients. A stepwise multivariate regression analysis was performed. Gender: male $=1$, female $=0$; Smoking: yes $=1$, no $=0$. Presence of hypertension: yes $=1$, no $=0$; Presence of dyslipidemia: yes $=1$, no $=0 ; \beta$ : partial regression coefficient.

NS, not significant; NI, not included; BMI, body mass index.

Table 5 Clinical characteristics of the study subjects with and without low eGFR $\left(<60 \mathrm{~mL} / \mathrm{min} / 1.73 \mathrm{~m}^{2}\right)$

\begin{tabular}{|c|c|c|c|}
\hline & $\begin{array}{c}\text { preserved eGFR } \\
\left(\geq 60 \mathrm{~mL} / \mathrm{min} / 1.73 \mathrm{~m}^{2}\right) \\
(\mathrm{n}=1178)\end{array}$ & $\begin{array}{c}\text { low eGFR } \\
\left(<60 \mathrm{~mL} / \mathrm{min} / 1.73 \mathrm{~m}^{2}\right) \\
(\mathrm{n}=270)\end{array}$ & $p$ \\
\hline Gender (male / female) & $716 / 462$ & $176 / 94$ & $\mathrm{NS}^{\mathrm{a}}$ \\
\hline Age (yr) & $59.7 \pm 9.6$ & $64.6 \pm 8.6$ & $<0.001$ \\
\hline Smoking (B.I. < 200 / $\geq 200$ ) & $606 / 564$ & $140 / 126$ & $\mathrm{NS}^{\mathrm{a}}$ \\
\hline Body mass index $\left(\mathrm{kg} / \mathrm{m}^{2}\right)$ & $24.4 \pm 3.7$ & $24.4 \pm 3.4$ & 0.0134 \\
\hline $\mathrm{HbA}_{1 \mathrm{C}}(\%)$ & $7.8 \pm 1.3$ & $7.4 \pm 1.1$ & $<0.001$ \\
\hline Duration of diabetes (yr) & $10.6 \pm 7.8$ & $13.5 \pm 8.6$ & $<0.001$ \\
\hline Presence of hypertension (\%) & $819(69.5 \%)$ & $234(86.7 \%)$ & $<0.001^{\mathrm{a}}$ \\
\hline Systolic blood pressure (mmHg) & $130 \pm 14$ & $135 \pm 16$ & $<0.001$ \\
\hline Diastolic blood pressure (mmHg) & $75 \pm 9$ & $77 \pm 11$ & 0.001 \\
\hline Presence of dyslipidemia (\%) & $858(72.8 \%)$ & $206(76.3 \%)$ & NS \\
\hline Presence of obesity (\%) & $460(39.0 \%)$ & $102(37.8 \%)$ & NS \\
\hline Total-cholesterol (mg/dL) & $202 \pm 35$ & $199 \pm 36$ & NS \\
\hline HDL-cholesterol (mg/dL) & $56 \pm 17$ & $53 \pm 15$ & 0.006 \\
\hline Triglyceride (mg/dL) & $105(26-2233)$ & $115.5(35-798)$ & NS \\
\hline Ln-triglyceride (mg/dL) & $4.70 \pm 0.58$ & $4.76 \pm 0.55$ & NS \\
\hline \multicolumn{4}{|l|}{ Administration of } \\
\hline Antidiabetic drugs (\%) & $866(73.5 \%)$ & $186(68.9 \%)$ & $\mathrm{NS}^{\mathrm{a}}$ \\
\hline Antihypertensive drugs (\%) & $419(35.6 \%)$ & $139(51.5 \%)$ & $<0.001^{\mathrm{a}}$ \\
\hline Anti-hyperlipidemic drugs (\%) & $271(23.0 \%)$ & $76(28.1 \%)$ & $\mathrm{NS}^{\mathrm{a}}$ \\
\hline \multicolumn{4}{|l|}{ Allele frequency $(\%)$} \\
\hline $\mathrm{G}$ & 90.7 & 93.7 & $0.028^{\mathrm{a}}$ \\
\hline A & 9.3 & 6.3 & $0.028^{\mathrm{a}}$ \\
\hline \multicolumn{4}{|l|}{ Genotype frequency (\%) } \\
\hline GG, GA, AA & $82.2 / 17.1 / 0.7$ & $87.4 / 12.6 / 0.0$ & $0.038(\mathrm{MRM})$ \\
\hline
\end{tabular}

Data are shown as numbers (\%) or means \pm SD. In the major allele's dominant and the recessive genetic models, the associations between the polymorphism and variables were evaluated with the $\chi^{2}$

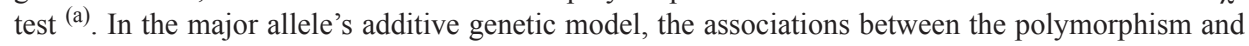
variables were evaluated with the Cochran-Armitage test. $p$-values over 0.05 were displayed as NS (not significant).

B. I., Brinkman's Index; MRM, major allele's recessive model Ln-, log-transformed. 
Table 6 Multivariate logistic regression analysis to identify independent determinants for low eGFR $\left(<60 \mathrm{~mL} / \mathrm{min} / 1.73 \mathrm{~m}^{2}\right)$

\begin{tabular}{lcccccc}
\hline \multicolumn{1}{c}{ Parameters } & \multicolumn{2}{c}{ Model 1} & & \multicolumn{2}{c}{ Model 2} \\
\cline { 2 - 3 } \cline { 6 - 7 } & Odds ratio $(95 \% \mathrm{CI})$ & $p$ value & & Odds ratio (95\%CI) & $p$ value \\
\hline Gender (male) & $1.22(0.91-1.63)$ & NS & & $1.22(0.91-1.64)$ & NS \\
Age (years) & $1.05(1.03-1.07)$ & $<0.001$ & & $1.05(1.03-1.07)$ & $<0.001$ \\
Duration of diabetes (years) & $1.03(1.01-1.05)$ & 0.002 & & $1.03(1.01-1.05)$ & 0.002 \\
HbA1c (\%) & $0.80(0.70-0.91)$ & 0.001 & & $0.80(0.70-0.91)$ & 0.001 \\
Body mass index $\left(\mathrm{kg} / \mathrm{m}^{2}\right)$ & $1.02(0.98-1.07)$ & NS & & $1.02(0.98-1.07)$ & NS \\
Presence of hypertension & $2.48(1.68-3.65)$ & $<0.001$ & & $2.48(1.68-3.65)$ & $<0.001$ \\
Presence of dyslipidemia & $1.23(0.89-1.72)$ & NS & & $1.23(0.89-1.72)$ & NS \\
-463G allele & $1.45(0.98-2.15)$ & 0.062 & & - & - & - \\
-436GG genotype & - & - & & $1.42(0.95-2.12)$ & 0.090 \\
\hline
\end{tabular}

Multivariate logistic regression analysis was done for 1448 type 2 diabetic patients to select variables significantly associated with an increase in the risk of low eGFR $\left(<60 \mathrm{ml} / \mathrm{min} / 1.73 \mathrm{~m}^{2}\right)$. The threshold of statistical significance was defined as $p<0.05$.

Model 1; gender, age, duration of diabetes, $\mathrm{HbA1c}$, body mass index, presence of hypertension, presence of dyslipidemia, and the number of $-436 \mathrm{G}$ allele were included as independent variables.

Model 2; gender, age, duration of diabetes, HbAlc, body mass index, presence of hypertension, presence of dyslipidemia, and the number of -436GG genotype were included as independent variables.

NS, not significant

(Supplementary Table 4). In addition, multiple logistic regression analyses showed that the number of $\mathrm{G}$ allele (OR 1.82; 95\% CI 1.05-3.16, $p=0.034$ ) as well as GG genotype (OR 1.81; 95\%CI 1.03-3.16, $p=0.038$ ) were independently associated with low eGFR $(<60$ $\mathrm{mL} / \mathrm{min} / 1.73 \mathrm{~m}^{2}$ ) after adjustment for conventional risk factors (Supplementary Table 5).

These findings suggest that $\mathrm{G}$ allele of the $M P O$ G-463A polymorphism is a susceptibility allele for kidney damage, especially for the development of macroalbuminuria and reduction of GFR in Japanese type 2 diabetic patients.

\section{Increase of MPO expression in the advanced stage of renal damage in $\mathrm{HFD}$-induced diabetic mice}

The findings of our human genomic study suggest that the $M P O \mathrm{G}-463 \mathrm{~A}$ polymorphism is associated with the presence of macroalbuminuria and negatively correlated with eGFR (Tables 3 and 4), but not with the presence of microalbuminuria (Table 2). To understand the association of MPO G-463A polymorphism with each stage of diabetic nephropathy, we examined the relationship between MPO expression and the severity of renal damage, by using two kinds of diabetes-related renal injury mouse models: HFD-induced glomerular injury to mimic the early stage of diabetic nephropathy; and an intraperitoneal protein overload model in HFDinduced obese mice as a model of proteinuria-induced tubulointerstitial damage in obese type 2 diabetes.
First, to elucidate the involvement of MPO in the pathogenesis of microalbuminuria in diabetes, we examined renal MPO expression in diabetic mice fed with a HFD for 12 weeks [19]. Mice fed a HFD developed an obese diabetic phenotype coupled with a renal phenotype of early stage diabetic nephropathy characterized by albuminuria and glomerular hypertrophy, but not with tubulointerstitial lesions or renal dysfunction (Fig. 1A-F). In real-time PCR, MPO expression was not detected at all in the kidneys of HFD-fed mice as well as ND-fed mice (Fig. 1F).

The progressive nature of proteinuric kidney disease, including diabetic nephropathy, is dependent on the degree of proteinuria-induced tubulointerstitial damage [20]. Therefore, to elucidate the involvement of MPO in the advanced stage of diabetic nephropathy, we examined MPO expression in the proteinuriainduced tubulointerstitial lesions in the HFD-induced diabetic mice. Although mice maintained on the HFD for 6 weeks had significant weight gain in addition to a significant increase in fasting blood glucose and glycated hemoglobin levels, there was no difference in serum cystatin $C$ levels (Fig. 2A-D). Next, to examine the effect of HFD on overt proteinuria-induced tubulointerstitial lesions, tubulointerstitial lesions were induced by equal volumes of protein overload in mice maintained on a ND or HFD for 6 weeks (Fig. 2E) [19]. In mice fed a ND, protein overload led to mild proximal tubular cell damage (Fig. 2F) with significant increases 
A

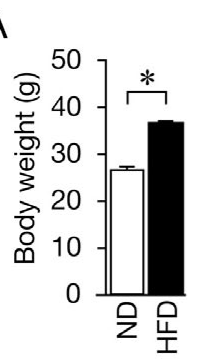

B

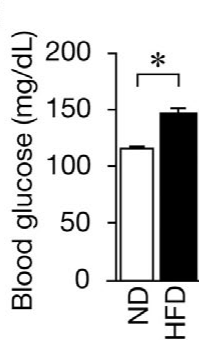

C

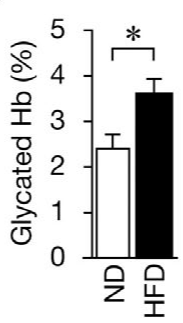

D

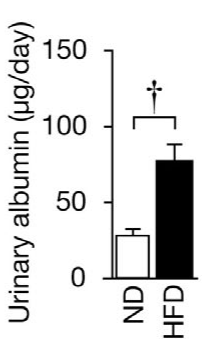

E

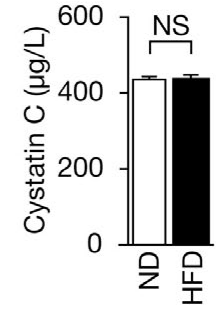

F

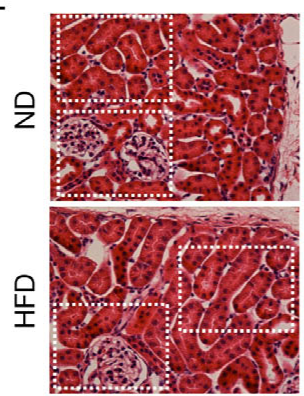

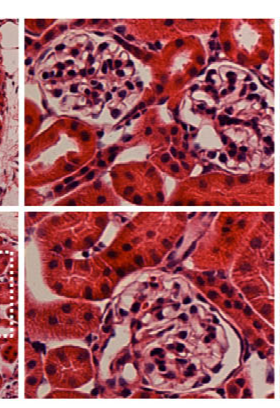

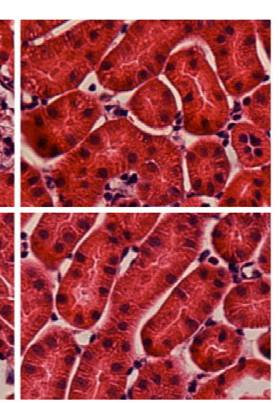

G

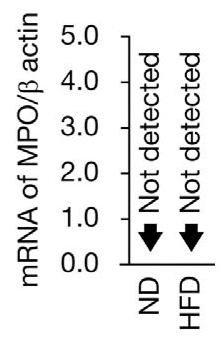

Fig. 1 (A-E) Body weight (A), blood glucose (B), glycated hemoglobin levels (C), urinary albumin excretion levels (D), and serum cystatin $\mathrm{C}$ levels (E) in each group of mice fed with a normal diet (ND) or high-fat diet (HFD) for 12 weeks. (F) Representative pictures of hematoxylin eosin (HE) staining in kidney sections from each group of mice. $(\mathrm{H})$ Renal mRNA expression levels of MPO determined by real-time PCR. mRNA of $\beta$ actin was used as an internal control. Data are mean \pm SEM $(\mathrm{n}=8) .{ }^{*} p<0.01$. $\dagger p<0.05$. NS: no significant. MPO: myeloperoxidase.

in mRNA expression of Ngal, MCP-1 and fibronectin, markers of proximal tubular cell damage, inflammation and fibrosis (Fig. 2G-I). No increases in serum cystatin C levels were observed (Fig. 2D). In contrast, in mice fed a HFD, protein overload caused more severe tubulointerstitial lesions with significant increases in renal mRNA expression of Ngal, MCP-1, fibronectin and serum cystatin $\mathrm{C}$ levels (Fig. 2E-I). These results suggest that the diabetic state markedly exacerbates proteinuria-induced tubulointerstitial damage.

In ND-fed mice, protein overload also caused an increase in MPO mRNA expression (Fig. 2J). Interestingly, this increase in MPO expression was further facilitated in the kidneys of HFD-induced diabetic mice (Fig. 2J), which was similar to changes observed in the expression of Ngal, MCP-1 and fibronectin (Fig. $2 \mathrm{G}-\mathrm{I})$. Furthermore, MPO expression was positively correlated with the serum cystatin $\mathrm{C}$ levels and mRNA expression levels of Ngal, MCP-1 and fibronectin (Fig. $2 \mathrm{~K}-\mathrm{N}$ ). Also, FFA-non-depleted BSA increased MPO expression in the whole kidney samples of mice. This change was not observed in all the samples from cultured podocytes, mesangial cells and proximal tubules (Fig. 2O). These results suggest that MPO is likely to be involved in the relatively advanced stage, rather than the early stage, of renal damage found in HFD-induced diabetic mice, and the infiltration of inflammatory cells is a principal reason for the increase in MPO expression in kidneys of mice with protein overload.

\section{Discussion}

This is the first report to examine the relationship of $M P O$ gene G-463A polymorphism and renal damage in a large cohort of type 2 diabetic patients, although there have been several studies showing that $M P O$ gene G-463A polymorphism is associated with coronary heart disease $[21,22]$. We revealed that the $G$ allele or GG genotype of this polymorphism could be a risk factor for both macroalbuminuria and the reduction of GFR in Japanese type 2 diabetic patients. The increased risk of renal damage associated with the presence of the $\mathrm{G}$ allele observed in the present study is in accordance with the previous studies showing that the G allele is associated with an increased expression of MPO [14, 15] and that MPO plays roles in the pathogenesis of several renal diseases such as acute immune complex crescentic glomerulonephritis [7], membranous glomerulonephritis [8], and ischemia/reperfusion injury [9].

In our human genomic study, the G-463A polymor- 

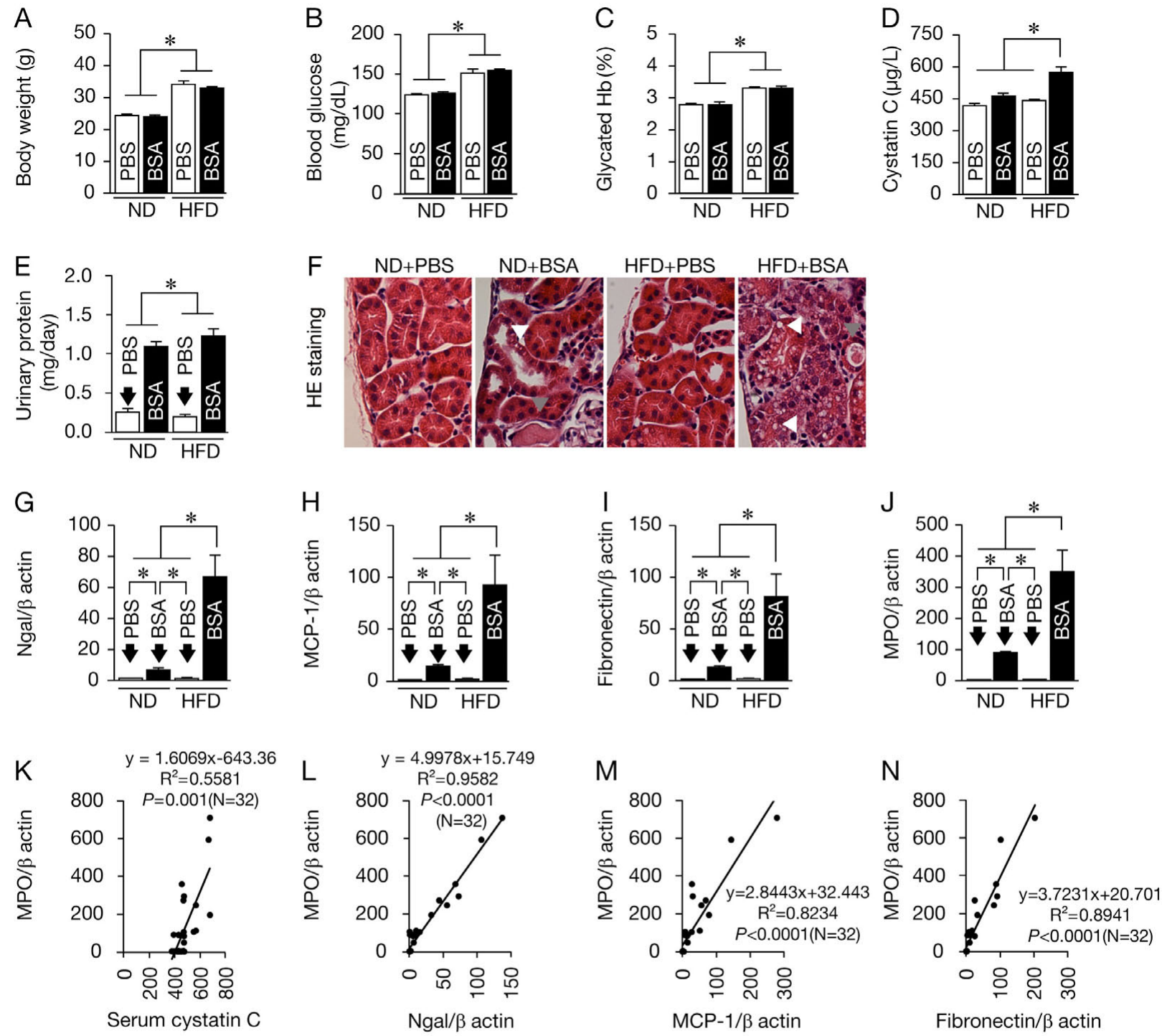

Serum cystatin C

$\mathrm{O}$

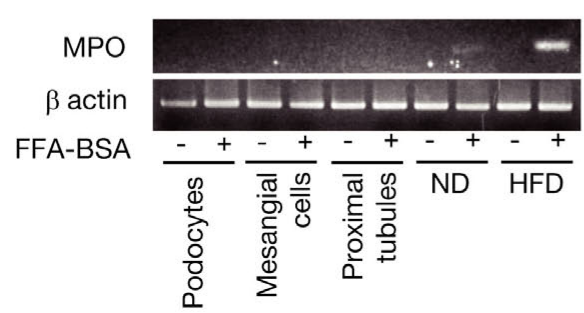

Fig. 2 (A-E) Body weight (A), blood glucose (B), glycated hemoglobin levels (C), serum cystatin C levels (D) and urinary protein excretion levels (E) in each group of mice at the end of the experimental period $(n=8)$. $(F)$ Representative pictures of hematoxylin eosin (HE) staining in kidney sections from each group of mice. (G-J) Renal mRNA expression levels of Ngal (G), MCP-1 $(\mathrm{H})$, fibronectin $(\mathrm{I})$ and MPO $(\mathrm{J})$ determined by real-time PCR. $\beta$ actin was used as an internal control. (K-N) Correlation between mRNA expression levels of MPO and serum cystatin C (K), Ngal (L), MCP-1 (M) or fibronectin (N). Data are mean \pm SEM. * $p<0.01$. PBS: phosphate-buffered saline; BSA: bovine serum albumin, protein overload model; ND: normal diet group; HFD: high-fat diet group; Ngal: Neutrophilgelatinase-associated lipocalin; MCP-1: monocyte chemoattractant protein-1; MPO: myeloperoxidase; FFA-BSA: free fatty acid-non-depleted BSA. (O) A representative picture showing the PCR products to detect MPO expressions in the samples from the cultured podocytes, mesangian cells and proximal tubular cells stimulated with/ without FFA-non-depleted albumin, and in the whole kidney samples from mice fed with ND or HFD with/without FFA-nondepleted albumin-overload. 
phism, which is known to positively regulate $M P O$ gene expression, was associated with the development of macroalbuminuria and the reduction of GFR, but not the appearance of microalbuminuria. In the animal study, MPO expression was significantly increased in the kidneys of HFD-induced diabetic mice with increased serum cystatin $\mathrm{C}$ levels and renal Ngal, MCP-1 and fibronectin expressions induced by protein load, but not in the kidneys of mice with microalbuminuria alone. Furthermore, MPO expression was significantly and positively correlated with the severity of protein loadinduced proximal tubular damage, inflammatory and fibrotic responses, and renal dysfunction. Also, MPO expression was not found in the cultured renal component cells exposed to FFA-non-depleted BSA, although it was detected in the whole kidney samples from protein-overloaded mice. Taken together, these results suggest that increase of MPO-positive inflammatory cells (i.e., neutrophils) and subsequent production of reactive oxygen species (ROS) may be involved in the advanced stage, rather than the early stage, of renal damage in HFD-induced diabetic mice. These experimental data were consistent with the results of our human genomic study. However, additional research using MPO knockout mice are needed to ascertain whether the diabetesrelated increases in MPO expression represent a marker for the severity of kidney damage or whether these changes play a pathological role in the development of diabetic nephropathy.

Although it is still speculative to regard MPO as a relevant pathogenetic factor for renal complications in diabetes, it is possible that MPO plays roles in the pathogenesis of diabetic nephropathy through the production of ROS and $\mathrm{HOCl} / \mathrm{OCl}^{-}$[1, 10-12], since increased production of ROS as well as $\mathrm{HOCl} / \mathrm{OCl}^{-}$ have been shown to promote renal injury [10-13]. In diabetes, MPO-derived ROS can accelerate the generation of advanced glycation end products (AGEs) and subsequent interaction with receptor for AGE (RAGE), which lead to renal injury [23, 24].

There are several limitations in the current study. First, the number of the study subjects was relatively small and the statistical power was not enough in the present study. Therefore, a replication study with a larger size would be necessary to confirm the hypothesis that this polymorphism is associated with the renal damage in type 2 diabetic patients.

Second, since all the subjects were recruited through hospitals, the observed association is not completely unrelated to population stratification and pleiotropic effects of this polymorphism. Furthermore, it might not appropriate to apply our findings to other race or ethnic groups, since all the subjects of this study were Japanese.

Third, it is possible we are not studying the actual disease-associated polymorphism. Polymorphisms tend to be linkage disequilibrium and thus the $M P O$ G-463A polymorphism may not be pathogenic but in linkage disequilibrium with another SNP that is pathogenic.

Fourth, the results of the mouse study did not allow concluding that increased MPO expression in diabetes is a causal factor in renal damage. Renal injury may be a cause of increased activity of neutrophils and macrophages, and higher MPO expression could be merely downstream effect. Additional research using MPO knockout mice are needed to make conclusions of a cause-effect relationship between MPO gene expression and renal damage. Similarly, our findings should be confirmed by experiments using other animal models for diabetes. In addition, animal models of renal injury are significantly different from kidney pathology in humans. The pattern of MPO expression and activity in human diabetic nephropathy is still unresolved. Although enhanced MPO activity has been detected in epiretinal membranes of patients with proliferative diabetic retinopathy [25], no reports exist on renal MPO expression in patients with diabetic nephropathy. The exact role of MPO in human diabetic nephropathy must be explored more extensively.

Finally, discovering a polymorphism-disease association does not directly lead to the improvement of risk prediction and clinical medicine. However, discovering genetic markers that are associated with disease risk would be an essential first step in applying genetic profiles to clinical medicine. Although approaches to predict a high-risk group using genetic profiles have not been established yet, the combined information about a number of susceptible variants including $M P O$ G-463A polymorphism could lead to the identification of subjects with high risk of diabetic nephropathy.

In conclusion, it is likely that the $\mathrm{G}$ allele of the $M P O \mathrm{G}-463$ A polymorphism is a susceptibility allele for renal injury in Japanese type 2 diabetic patients.

\section{Declaration of Competing Interests}

Nothing to declare. 


\section{Author contributions}

N.K. and S.K. conceived and designed the experiments, researched data, and wrote the manuscript. H.K. and T.U. researched data, reviewed and edited the manuscript. Y.Y. designed the research and analyzed the data. A.K., H.M, and I.S. contributed to the interpretation of the data and reviewed the manuscript. All authors reviewed and approved the report.

\section{Acknowledgements}

Co-investigators, in addition to the authors of this study, included Dr. Ikki Shimizu, who directed Department of Diabetology, The Sakakibara Heart Institute of Okayama,; Dr. Keizo Ohno, who directed Ehime Prefectural Imabari Hospital; Dr. Takeshi Osonoi, who directed Naka Memorial Clinic; Dr. Koichi Kawai, who directed Kawai Clinic; Dr. Fukashi Ishibashi, who directed Ishibashi Clinic; Dr. Kenichi Imamura, who directed Imamura Clinic; Prof. Ryuzo Kawamori (Sportology Center, Juntendo University Graduate School of Medicine) and Prof. Munehide Matsuhisa (Diabetes Therapeutics and Research Center, Tokushima University), who contributed to the discussion.

Supplementary Table 1 Clinical characteristics of the study subjects with at least 10 years' duration of diabetes (G/G vs. G/A or A/A)

\begin{tabular}{|c|c|c|c|c|}
\hline$G-463 \mathrm{~A}$ polymorphism of the myeloperoxidase (MPO) gene & $\begin{array}{c}\text { Total } \\
(\mathrm{n}=715)\end{array}$ & $\begin{array}{c}\mathrm{G} / \mathrm{G} \\
(\mathrm{n}=598)\end{array}$ & $\begin{array}{c}\mathrm{G} / \mathrm{A} \text { or } \mathrm{A} / \mathrm{A} \\
(\mathrm{n}=117)\end{array}$ & $p$ value \\
\hline Gender (male / female) & $461 / 254$ & $391 / 207$ & $70 / 47$ & NS \\
\hline Age (years) & $63.3 \pm 8.3$ & $63.6 \pm 8.1$ & $61.6 \pm 9.4$ & 0.021 \\
\hline Smoking status $($ B.I. $<200 / \geq 200)$ & $360 / 346$ & $293 / 297$ & $67 / 49$ & NS \\
\hline Presence of obesity $(\%)$ & $240(33.6 \%)$ & $199(33.3 \%)$ & $41(35.0 \%)$ & NS \\
\hline Body mass index $\left(\mathrm{kg} / \mathrm{m}^{2}\right)$ & $24.0 \pm 3.4$ & $24.0 \pm 3.4$ & $24.2 \pm 3.8$ & NS \\
\hline $\mathrm{HbA}_{1 \mathrm{C}}(\%)$ & $7.8 \pm 1.1$ & $7.8 \pm 1.2$ & $7.9 \pm 1.1$ & NS \\
\hline Duration of diabetes (years) & $17.4 \pm 6.9$ & $17.3 \pm 6.8$ & $17.6 \pm 7.2$ & NS \\
\hline Presence of hypertension (\%) & $538(75.2 \%)$ & $450(75.3 \%)$ & $88(75.2 \%)$ & NS \\
\hline Systolic blood pressure (mmHg) & $131 \pm 14$ & $132 \pm 14$ & $131 \pm 14$ & NS \\
\hline Diastolic blood pressure (mmHg) & $75 \pm 10$ & $74 \pm 10$ & $75 \pm 9$ & NS \\
\hline Presence of dyslipidemia (\%) & $513(71.7 \%)$ & $424(70.9 \%)$ & $89(76.1 \%)$ & NS \\
\hline Total-cholesterol (mg/dL) & $200 \pm 36$ & $198 \pm 35$ & $208 \pm 39$ & 0.008 \\
\hline HDL-cholesterol (mg/dL) & $57 \pm 18$ & $57 \pm 18$ & $58 \pm 18$ & NS \\
\hline Triglyceride (mg/dL) & $104(26-2233)$ & $104(26-798)$ & $103(29-2233)$ & NS \\
\hline Ln-Triglyceride (mg/dL) & $4.67 \pm 0.57$ & $4.67 \pm 0.56$ & $4.68 \pm 0.66$ & NS \\
\hline $\mathrm{Cr}(\mathrm{mg} / \mathrm{dL})$ & $0.91 \pm 2.64$ & $0.95 \pm 2.89$ & $0.75 \pm 0.27$ & NS \\
\hline eGFR (mL/min/1.73m²) & $73.6 \pm 21.5$ & $72.3 \pm 20.5$ & $80.2 \pm 25.1$ & $<0.001$ \\
\hline $\mathrm{eGFR}<60 \mathrm{~mL} / \mathrm{min} / 1.73 \mathrm{~m}^{2}(\%)$ & $173(24.2 \%)$ & $154(25.8 \%)$ & $19(16.2 \%)$ & 0.028 \\
\hline Urinary albumin excretion index (mg/gCr) & $20.6(0-4023)$ & $20.3(0-4023)$ & $20.9(0.5-3573)$ & NS \\
\hline $\mathrm{Ln}-\mathrm{UAE}(\mathrm{mg} / \mathrm{gCr})$ & $3.32 \pm 1.61$ & $3.33 \pm 1.62$ & $3.28 \pm 1.57$ & NS \\
\hline Proteinuria (normo/micro/macro) & $416 / 231 / 68$ & $350 / 186 / 62$ & $66 / 45 / 6$ & - \\
\hline Albuminuria >30mg/gCr (\%) & $299(41.8 \%)$ & $248(41.5 \%)$ & $51(43.6 \%)$ & NS \\
\hline Albuminuria $>300 \mathrm{mg} / \mathrm{gCr}(\%)$ & $68(9.5 \%)$ & $62(10.4 \%)$ & $5(4.3 \%)$ & 0.037 \\
\hline Antidiabetic drugs (yes / no) & $541(75.7 \%)$ & $445(74.4 \%)$ & $96(82.1 \%)$ & NS \\
\hline Antihypertensive drugs (yes / no) & $308(43.1 \%)$ & $259(43.3 \%)$ & $49(41.9 \%)$ & NS \\
\hline Antihyperlipidemic drugs (yes / no) & $164(22.9 \%)$ & $142(23.7 \%)$ & $22(18.8 \%)$ & NS \\
\hline Serum MPO $(\mathrm{ng} / \mathrm{mL})$ & $\begin{array}{c}311(12-2480) \\
(n=122)\end{array}$ & $\begin{array}{c}335(12-2480) \\
(\mathrm{n}=111)\end{array}$ & $\begin{array}{c}223(47-743) \\
(\mathrm{n}=11)\end{array}$ & NS \\
\hline Ln-serum MPO (ng/mL) & $5.79 \pm 0.99$ & $5.82 \pm 1.00$ & $5.45 \pm 0.83$ & NS \\
\hline
\end{tabular}

Data are shown as numbers or means \pm SD. All the subjects were divided into 2 groups based on the major allele's recessive genetic models ( $G G$ genotype $v s$. $G A+A A$ genotype) and the parameters were compared among the groups. Quantitative data between the groups were compared by the 2-tailed unpaired $t$ test and categorical data were analyzed with the $\chi^{2}$ test. Nephropathy was graded as follows: normoalbuminuria, urinary albumin excretion less than $30 \mathrm{mg} / \mathrm{g} \mathrm{Cr}$; microalbuminuria, 30 to $300 \mathrm{mg} / \mathrm{g}$ Cr; or macroalbuminuria, more than $300 \mathrm{mg} / \mathrm{g}$ Cr. $p$-values over 0.05 were displayed as NS (not significant).

B. I., Brinkman’s Index; Ln-, log-transformed; UAE, Urinary albumin excretion index; MPO, myeloperoxidase 
Supplementary Table 2 Clinical characteristics of the study subjects with at least 10 years' duration of diabetes (proteinuria (-) vs. proteinuria (+))

\begin{tabular}{|c|c|c|c|c|}
\hline & $\begin{array}{c}\text { Total } \\
(\mathrm{n}=715)\end{array}$ & $\begin{array}{l}\text { proteinuria }(-) \\
(\mathrm{n}=648)\end{array}$ & $\begin{array}{l}\text { proteinuria }(+) \\
(\mathrm{n}=67)\end{array}$ & $p$ \\
\hline Gender (male / female) & $461 / 254$ & $417 / 231$ & $44 / 23$ & $\mathrm{NS}^{\mathrm{a}}$ \\
\hline Age (yr) & $63.3 \pm 8.3$ & $63.2 \pm 8.3$ & $64.2 \pm 8.0$ & NS \\
\hline Smoking (B.I. $<200 / \geq 200$ ) & $346 / 360$ & $311 / 328$ & $35 / 32$ & $\mathrm{NS}^{\mathrm{a}}$ \\
\hline Body mass index $\left(\mathrm{kg} / \mathrm{m}^{2}\right)$ & $24.0 \pm 3.4$ & $24.0 \pm 3.4$ & $24.5 \pm 3.2$ & NS \\
\hline $\mathrm{HbA}_{1 \mathrm{C}}(\%)$ & $7.8 \pm 1.1$ & $7.8 \pm 1.1$ & $8.0 \pm 1.6$ & NS \\
\hline Duration of diabetes (yr) & $17.4 \pm 6.9$ & $17.4 \pm 6.9$ & $16.9 \pm 7.0$ & NS \\
\hline Presence of hypertension $(\%)$ & $538(75.2 \%)$ & $480(74.1 \%)$ & $58(86.6 \%)$ & $0.024^{\mathrm{a}}$ \\
\hline Systolic blood pressure $(\mathrm{mmHg})$ & $131 \pm 14$ & $131 \pm 13$ & $138 \pm 17$ & 0.001 \\
\hline Diastolic blood pressure (mmHg) & $75 \pm 10$ & $74 \pm 9$ & $75 \pm 11$ & NS \\
\hline Presence of dyslipidemia (\%) & $513(71.7 \%)$ & $462(71.3 \%)$ & $51(76.1 \%)$ & NS \\
\hline Presence of obesity $(\%)$ & $240(33.6 \%)$ & $215(33.2 \%)$ & $25(37.3 \%)$ & NS \\
\hline Total-cholesterol (mg/dL) & $200 \pm 36$ & $199 \pm 35$ & $206 \pm 42$ & NS \\
\hline HDL-cholesterol (mg/dL) & $57 \pm 18$ & $57 \pm 18$ & $55 \pm 15$ & NS \\
\hline Triglyceride $(\mathrm{mg} / \mathrm{dL})$ & $104(26-2233)$ & $103(26-2233)$ & $124(38-516)$ & NS \\
\hline Ln-triglyceride (mg/dL) & $4.67 \pm 0.57$ & $4.65 \pm 0.57$ & $4.76 \pm 0.56$ & NS \\
\hline \multicolumn{5}{|l|}{ Administration of } \\
\hline Antidiabetic drugs (\%) & $542(75.8 \%)$ & $494(76.2 \%)$ & $48(71.6 \%)$ & $\mathrm{NS}^{\mathrm{a}}$ \\
\hline Antihypertensive drugs (\%) & $308(43.1 \%)$ & $263(40.6 \%)$ & $45(67.2 \%)$ & $<0.0001^{\mathrm{a}}$ \\
\hline Anti-hyperlipidemic drugs (\%) & $164(22.9 \%)$ & $143(22.1 \%)$ & $21(31.3 \%)$ & $\mathrm{NS}^{\mathrm{a}}$ \\
\hline \multicolumn{5}{|l|}{ Allele frequency $(\%)$} \\
\hline $\mathrm{G}$ & 91.7 & 91.2 & 96.3 & $0.047^{\mathrm{a}}$ \\
\hline $\mathrm{A}$ & 8.3 & 8.8 & 4.7 & $0.047^{\mathrm{a}}$ \\
\hline \multirow{3}{*}{$\begin{array}{l}\text { Genotype frequency (\%) } \\
\text { GG, GA, AA }\end{array}$} & & & & NS (MDM) \\
\hline & $83.6 / 16.1 / 0.3$ & $82.7 / 17.0 / 0.3$ & $92.5 / 7.5 / 0.0$ & $0.037(\mathrm{MRM})$ \\
\hline & $598 / 115 / 2$ & $536 / 110 / 2$ & $62 / 5 / 0$ & 0.038 (MAM) \\
\hline
\end{tabular}

Data are shown as numbers (\%) or means \pm SD. In the major allele's dominant and the recessive genetic models, the associations between the polymorphism and variables were evaluated with the $\chi^{2}$ test ${ }^{(a)}$. In the major allele's additive genetic model, the associations between the polymorphism and variables were evaluated with the Cochran-Armitage test. $p$-values over 0.05 were displayed as NS (not significant).

B. I., Brinkman's Index; Ln-, log-transformed; MDM, major allele's dominant model; MRM, major allele's recessive model; MAM, major allele's additive model.

Supplementary Table 3 Multivariate logistic regression analysis to identify independent determinants for proteinuria in type 2 diabetic subjects with at least 10 years' duration of diabetes

\begin{tabular}{|c|c|c|c|c|}
\hline \multirow{2}{*}{ Parameters } & \multicolumn{2}{|c|}{ Model 1} & \multicolumn{2}{|c|}{ Model 2} \\
\hline & Odds ratio $(95 \% \mathrm{CI})$ & $p$ value & Odds ratio $(95 \% \mathrm{CI})$ & $p$ value \\
\hline Gender (male) & $1.12(0.65-1.93)$ & NS & $1.12(0.65-1.93)$ & NS \\
\hline Age (years) & $1.02(0.99-1.06)$ & NS & $1.02(0.99-1.06)$ & NS \\
\hline Duration of diabetes (years) & $0.99(0.95-1.03)$ & NS & $0.99(0.95-1.03)$ & NS \\
\hline $\operatorname{HbA} 1 \mathrm{c}(\%)$ & $1.21(0.98-1.49)$ & NS & $1.21(0.98-1.49)$ & NS \\
\hline Body mass index $\left(\mathrm{kg} / \mathrm{m}^{2}\right)$ & $1.03(0.95-1.11)$ & NS & $1.03(0.95-1.11)$ & NS \\
\hline Presence of hypertension & $2.18(1.04-4.59)$ & 0.039 & $2.18(1.04-4.58)$ & 0.040 \\
\hline Presence of dyslipidemia & $1.21(0.65-2.21)$ & NS & $1.20(0.66-2.21)$ & NS \\
\hline$-463 \mathrm{G}$ allele & $2.63(1.63-6.70)$ & 0.043 & - & - \\
\hline -436GG genotype & - & - & $2.64(1.03-6.76)$ & 0.044 \\
\hline
\end{tabular}

Multivariate logistic regression analysis was done for 715 patients to select variables significantly associated with an increase in the risk of proteinuria. The threshold of statistical significance was defined as $p<0.05$.

Model 1; gender, age, duration of diabetes, $\mathrm{HbAlc}$, body mass index, presence of hypertension, presence of dyslipidemia, and the number of $-436 \mathrm{G}$ allele were included as independent variables.

Model 2; gender, age, duration of diabetes, $\mathrm{HbA1c}$, body mass index, presence of hypertension, presence of dyslipidemia, and the number of -436GG genotype were included as independent variables.

Abbreviations: NS, not significant 
Supplementary Table 4 Clinical characteristics of the study subjects with at least 10 years' duration of diabetes (high eGFR vs. low eGFR)

\begin{tabular}{|c|c|c|c|c|}
\hline & $\begin{array}{c}\text { Total } \\
(\mathrm{n}=715)\end{array}$ & $\begin{array}{c}\text { preserved eGFR } \\
\left(\geq 60 \mathrm{~mL} / \mathrm{min} / 1.73 \mathrm{~m}^{2}\right) \\
(\mathrm{n}=542)\end{array}$ & $\begin{array}{c}\text { low eGFR } \\
\left(<60 \mathrm{~mL} / \mathrm{min} / 1.73 \mathrm{~m}^{2}\right) \\
(\mathrm{n}=173)\end{array}$ & $p$ \\
\hline Gender (male / female) & $461 / 254$ & $348 / 194$ & $113 / 60$ & $\mathrm{NS}^{\mathrm{a}}$ \\
\hline Age (yr) & $63.3 \pm 8.3$ & $62.3 \pm 8.2$ & $66.3 \pm 8.0$ & $<0.001$ \\
\hline Smoking (B.I. $<200 / \geq 200$ ) & $346 / 360$ & $261 / 276$ & $99 / 70$ & $0.024^{\mathrm{a}}$ \\
\hline Body mass index $\left(\mathrm{kg} / \mathrm{m}^{2}\right)$ & $24.0 \pm 3.4$ & $24.0 \pm 3.5$ & $24.0 \pm 3.3$ & NS \\
\hline $\mathrm{HbA}_{1 \mathrm{C}}(\%)$ & $7.8 \pm 1.1$ & $7.9 \pm 1.2$ & $7.5 \pm 1.0$ & $<0.001$ \\
\hline Duration of diabetes (yr) & $17.4 \pm 6.9$ & $17.1 \pm 6.7$ & $18.2 \pm 7.3$ & NS \\
\hline Presence of hypertension (\%) & $538(75.2 \%)$ & $383(70.7 \%)$ & $155(89.6 \%)$ & $<0.001^{\mathrm{a}}$ \\
\hline Systolic blood pressure (mmHg) & $131 \pm 14$ & $130 \pm 13$ & $135 \pm 15$ & $<0.001$ \\
\hline Diastolic blood pressure $(\mathrm{mmHg})$ & $75 \pm 10$ & $74 \pm 9$ & $76 \pm 12$ & 0.027 \\
\hline Presence of dyslipidemia (\%) & $513(71.7 \%)$ & $385(71.0 \%)$ & $128(74.0 \%)$ & NS \\
\hline Presence of obesity $(\%)$ & $240(33.6 \%)$ & $184(33.9 \%)$ & $56(32.4 \%)$ & NS \\
\hline Total-cholesterol (mg/dL) & $200 \pm 36$ & $201 \pm 35$ & $198 \pm 37$ & NS \\
\hline HDL-cholesterol (mg/dL) & $57 \pm 18$ & $58 \pm 18$ & $54 \pm 15$ & 0.038 \\
\hline Triglyceride (mg/dL) & $104(26-2233)$ & $105(26-2233)$ & $115.5(35-798)$ & NS \\
\hline Ln-triglyceride (mg/dL) & $4.67 \pm 0.57$ & $4.65 \pm 0.58$ & $4.73 \pm 0.56$ & NS \\
\hline \multicolumn{5}{|l|}{ Administration of } \\
\hline Antidiabetic drugs (\%) & $542(75.8 \%)$ & $422(77.9 \%)$ & $120(69.4 \%)$ & $0.023^{\mathrm{a}}$ \\
\hline Antihypertensive drugs (\%) & $308(43.1 \%)$ & $210(38.7 \%)$ & $98(56.4 \%)$ & $<0.001^{\mathrm{a}}$ \\
\hline Anti-hyperlipidemic drugs (\%) & $164(22.9 \%)$ & $115(21.2 \%)$ & $50(28.9 \%)$ & $0.037^{\mathrm{a}}$ \\
\hline \multicolumn{5}{|l|}{ Allele frequency $(\%)$} \\
\hline $\mathrm{G}$ & 91.7 & 90.8 & 94.5 & $0.029^{\mathrm{a}}$ \\
\hline A & 8.3 & 9.2 & 5.5 & $0.029^{\mathrm{a}}$ \\
\hline Genotype frequency $(\%)$ & & & & NS (MDM) \\
\hline \multirow[t]{2}{*}{ GG, GA, AA } & $83.6 / 16.1 / 0.3$ & $81.9 / 17.7 / 0.4$ & $89.0 / 11.0 / 0$ & $0.028(\mathrm{MRM})$ \\
\hline & $598 / 115 / 2$ & 444 / 96 / 2 & $154 / 19 / 0$ & 0.024 (MAM) \\
\hline
\end{tabular}

Data are shown as numbers $(\%)$ or means \pm SD. In the major allele's dominant and the recessive genetic models, the associations between the polymorphism and variables were evaluated with the $\chi^{2}$ test ${ }^{(a)}$. In the major allele's additive genetic model, the associations between the polymorphism and variables were evaluated with the Cochran-Armitage test.

p-values over 0.05 were displayed as NS (not significant). B. I., Brinkman's Index; Ln-, log-transformed; MDM, major allele's dominant model; MRM, major allele's recessive model; MAM, major allele's additive model.

Supplementary Table 5 Multivariate logistic regression analysis to identify independent determinants for low eGFR (< $60 \mathrm{~mL} / \mathrm{min} / 1.73 \mathrm{~m}^{2}$ ) in type 2 diabetic subjects with at least 10 years' duration of diabetes

\begin{tabular}{|c|c|c|c|c|}
\hline \multirow{2}{*}{ Parameters } & \multicolumn{2}{|c|}{ Model 1} & \multicolumn{2}{|c|}{ Model 2} \\
\hline & Odds ratio $(95 \% \mathrm{CI})$ & $p$ value & Odds ratio $(95 \% \mathrm{CI})$ & $p$ value \\
\hline Gender (male) & $1.60(1.00-2.58)$ & NS & $1.61(1.00-2.58)$ & NS \\
\hline Age (years) & $1.05(1.03-1.08)$ & $<0.001$ & $1.05(1.03-1.08)$ & $<0.001$ \\
\hline Smoking (B.I. $\geq 200$ ) & $0.53(0.34-0.84)$ & 0.006 & $0.53(0.34-0.84)$ & 0.006 \\
\hline $\mathrm{HbA1c}(\%)$ & $0.74(0.61-0.90)$ & 0.002 & $0.74(0.61-0.90)$ & 0.002 \\
\hline Body mass index $\left(\mathrm{kg} / \mathrm{m}^{2}\right)$ & $1.00(0.95-1.06)$ & NS & $1.00(0.95-1.06)$ & NS \\
\hline Presence of hypertension & $3.16(1.84-5.43)$ & $<0.001$ & $3.16(1.84-5.42)$ & $<0.001$ \\
\hline Presence of dyslipidemia & $1.17(0.76-1.79)$ & NS & $1.17(0.77-1.80)$ & NS \\
\hline$-463 \mathrm{G}$ allele & $1.82(1.05-3.16)$ & 0.034 & - & - \\
\hline -436GG genotype & - & - & $1.81(1.03-3.16)$ & 0.038 \\
\hline
\end{tabular}

Multivariate logistic regression analysis was done for 715 type 2 diabetic patients to select variables significantly associated with an increase in the risk of proteinuria. The threshold of statistical significance was defined as $p<0.05$.

Model 1; gender, age, smoking status, HbAlc, body mass index, presence of hypertension, presence of dyslipidemia, and the number of $-436 \mathrm{G}$ allele were included as independent variables. Model 2; gender, age, smoking status, HbA1c, body mass index, presence of hypertension, presence of dyslipidemia, and the number of -436GG genotype were included as independent variables. NS, not significant 


\section{References}

1. Klebanoff SJ (1980) Oxygen metabolism and the toxic properties of phagocytes. Ann Intern Med 93: 480-489.

2. Daugherty A, Dunn JL, Rateri DL, Heinecke JW (1994) Myeloperoxidase, a catalyst for lipoprotein oxidation, is expressed in human atherosclerotic lesions. J Clin Invest 94: 437-444.

3. Zhang R, Brennan ML, Shen Z, McPherson JC, Schmitt D, et al. (2002) Myeloperoxidase functions as a major enzymatic catalyst for initiation of lipid peroxidation at sites of inflammation. J Biol Chem 277: 46116-46122.

4. Podrez EA, Abu-Soud HM, Hazen SL (2000) Myeloperoxidase generated oxidants and atherosclerosis. Free Radic Biol Med 28: 1717-1725.

5. Zhang R, Shen Z, Nauseef WM, Hazen SL (2002) Defects in leukocyte-mediated initiation of lipid peroxidation in plasma as studied in myeloperoxidase-deficient subjects: systematic identification of multiple endogenous diffusible substrates for Myeloperoxidase in plasma. Blood 99: 1802-1810.

6. Malle E, Buch T, Grone HJ (2003) Myeloperoxidase in kidney disease. Kidney Int 64: 1956-1967.

7. Odobasic D, Kitching AR, Semple TJ, Holdsworth SR (2007) Endogenous myeloperoxidase promotes neutrophilmediated renal injury, but attenuates T cell immunity inducing crescentic glomerulonephritis. J Am Soc Nephrol 18: 760-770.

8. GroneHJ, GroneEF, MalleE(2002)Immunohistochemical detection of hypochlorite-modified proteins in glomeruli of human membranous glomerulonephritis. Lab Invest 82: 5-14.

9. Matthijsen RA, Huugen D, Hoebers NT, deVries B, Peutz-Kootstra CJ, et al. (2007) Myeloperoxidase is critically involved in the induction of organ damage after renal ischemia reperfusion. Am J Pathol 171: 17431752.

10. Ha H, Lee HB (2001) Oxidative stress in diabetic nephropathy: basic and clinical information. Curr Diab Rep 1: 282-287.

11. Kitada M, Koya D, Sugimoto T, Isono M, Araki S, et al. (2003) Translocation of glomerular p47phox and p67phox by protein kinase C-beta activation is required for oxidative stress in diabetic nephropathy. Diabetes 52: 2603-2614.

12. Onozato ML, Tojo A, Goto A, Fujita T, Wilcox CS (2002) Oxidative stress and nitric oxide synthase in rat diabetic nephropathy: effects of ACEI and ARB. Kidney Int 61: 186-194.

13. Asaba K, Tojo A, Onozato ML, Goto A, Quinn MT, et al. (2005) Effects of NADPH oxidase inhibitor in diabetic nephropathy. Kidney Int 67: 1890-1898.

14. Piedrafita FJ, Molander RB, Vansant G, Orlova EA, Pfhal M, et al. (1996) An Alu element in the myeloperoxidase promoter contains a composite SP1-thyroid hor- mone-retinoic acid response element. J Biol Chem 271: 14412-14420.

15. Reynolds WF, Chang E, Douer E, Ball ED, Kanda V (1997) An allelic association implicates myeloperoxidase in the etiology of acute promyelocytic leukemia. Blood 90: 2730-2737.

16. The Committee of the Japan Diabetes Society on the Diagnostic Criteria of Diabetes Mellitus (2010) Report of the Committee on the Classification and Diagnostic Criteria of Diabetes Mellitus. J Diabetes Invest 1: 212228.

17. Matsuo S, Imai E, Horio M, Yasuda Y, Tomita K, et al. (2009) Collaborators developing the Japanese equation for estimated GFR. Revised equations for estimated GFR from serum creatinine in Japan. Am J Kidney Dis 53: 982-992.

18. Yamada Y, Izawa H, Ichihara S, Takatsu F, Ishihara H, et al. (2002) Prediction of the risk of myocardial infarction from polymorphisms in candidate genes. $N$ Engl J Med 347: 1916-1923.

19. Tanaka Y, Kume S, Araki S, Isshiki K, Chin-Kanasaki M, et al. (2011) Fenofibrate, a PPAR $\alpha$ agonist, has renoprotective effects in mice by enhancing renal lipolysis. Kidney Int 79: 871-882.

20. Risdon RA, Sloper JC, De Wardener HE (1968) Relationship between renal function and histological changes found in renal-biopsy specimens from patients with persistent glomerular nephritis. Lancet 2(7564): 363-366.

21. Nikpoor B, Turecki G, Fournier C, Theroux P, Rouleau GA (2001) A functional myeloperoxidase polymorphic variant is associated with coronary artery disease in French-Canadians. Am Heart J 142: 336-339.

22. Asselbergs FW, Reynolds WF, Cohen-Tervaert JW, Jessurun GA, Tio RA (2004) Myeloperoxidase polymorphism related to cardiovascular events in coronary artery disease. Am J Med 116: 429-430.

23. Anderson MM, Requenta JR, Crowley JR, Thorpe SR, Heinecke JW (1999) The myeloperoxidase system of human phagocytes generates $\mathrm{Ne}$-(carboxymethyl)lysine on proteins: a mechanism for producing advanced glycation end products at sites of inflammation. $J$ Clin Invest 104:103-113.

24. Horie K, Miyata T, Maeda K, Miyata S, Sugiyama S, et al. (1997) Immunohistochemical colocalization of glycoxidation products and lipid peroxidation products in diabetic renal glomerular lesions. Implication for glycoxidative stress in the pathogenesis of diabetic nephropathy. J Clin Invest 100: 2995-3004.

25. Augustin AJ, Spitznas M, Koch F, Grus F, Bocker T (1995) Indicators of oxidative tissue damage and inflammatory activity in epiretinal membranes of proliferative diabetic retinopathy, proliferative vitreoretinopathy and macular pucker. Ger J Ophthalmol 4: 47-51. 